\title{
Neisseria gonorrhoeae: un agente causal infrecuente de celulitis periorbitaria en un niño
} Neisseria gonorrhoeae: an infrequent causal agent of periorbital cellulitis in a child

\author{
Dra. Rocío del P. Pereira-Ospina ${ }^{a}$, Dr. Javier Y. Pinzón-Salamanca ${ }^{a}$ Dr. José M. Suescún-Vargas ${ }^{a} y$ \\ Dra. Yuli Guzmán-Pradoa
}

\begin{abstract}
RESUMEN
La celulitis periorbitaria es una patología muy frecuente en la población pediátrica. Se define como la infección que compromete los tejidos blandos adyacentes a la órbita sin atravesar el septum orbitario. Después de la introducción de la vacuna contra Haemophilus influenzae, los patógenos involucrados, generalmente, son cocos Gram-positivos.

A continuación, se presenta un caso de celulitis periorbitaria asociada a conjuntivitis purulenta por Neisseria gonorrhoeae en un niño de 2 años y 10 meses. Existen pocos casos descritos en la literatura en los que este microorganismo aparece como agente causal de celulitis periorbitaria. Con este caso, se quiere resaltar la importancia de la toma de cultivo en los pacientes que concomitantemente presenten conjuntivitis bacteriana y secreción purulenta, ya que esto facilitó el diagnóstico de esta patología por un agente etiológico poco frecuente.

Palabras clave: celulitis periorbitaria, Neisseria gonorrhoeae, infecciones de los tejidos blandos, niño.
\end{abstract}

\begin{abstract}
Periorbital cellulitis is a very common disease in pediatric population, it describes an infection involving the adjacent soft tissues anterior to the orbital septum. Pathogens involved are generally Gram-positive cocci after introduction of Haemophilus influenzae vaccine.

We report a case of Neisseria gonorrhoeae periorbital cellulitis associated with bacterial conjunctivitis in a child. There are few cases reported in the literature with this microorganism as the causal agent. With this case, we would like to emphasize the importance todoaculture of theocularsecretion(ifitexists) because this allowed us to determine an infrequent agent of this disease. Key words: periorbital cellulitis, Neisseria gonorrhoeae, soft tissue infections, child.
\end{abstract}

http:/ / dx.doi.org/10.5546/ aap.2017.e243

Cómo citar: Pereira-Ospina RP, Pinzón-Salamanca JY, Suescún-Vargas JM, et al. Neisseria gonorrhoeae: un agente causal infrecuente de celulitis periorbitaria en un niño. Arch Argent Pediatr 2017;115(4):e243-e246.

a. Departamento de Educación e Investigación, Instituto Roosevelt, Bogotá, Colombia.

\section{Correspondencia:}

Dra. Rocío del P. Pereira Ospina:

rpereira@ioir.org.co; rochi_1547@hotmail.com

Financiamiento: Ninguno.

Conflicto de intereses: Ninguno que declarar.

Recibido: 11-11-2016

Aceptado: 13-3-2017

\section{INTRODUCCIÓN}

Para entender el concepto de celulitis periorbitaria, se debe hacer referencia a la anatomía ocular. El contenido de la órbita y el tejido blando del párpado están separados por el septum orbitario, que constituye una barrera anatómica que impide el paso de infecciones a nivel intraocular. Todo lo anterior al septum es considerado periorbitario o preseptal y lo posterior a este es la órbita propiamente dicha. ${ }^{1,2}$

La celulitis periorbitaria es una infección que compromete los tejidos blandos de los párpados sin atravesar el septum orbitario. Los signos y síntomas que se evidencian en estos pacientes son aparición de edema, eritema y calor de los párpados, que puede estar acompañado o no de fiebre. $^{2}$

Varios son los agentes causales de esta patología y, luego de la introducción de la vacuna contra Haemophilus influenzae tipo b, se observó un aumento de Gram-positivos con respecto a Gram-negativos. Los de mayor prevalencia fueron Staphylococcus aureus, Streptococcus pyogenes y Streptococcus pneumoniae seguidos de Gramnegativos (como Haemophilus influenzae no b). ${ }^{3}$

\section{CASO CLÍNICO}

Paciente masculino de dos años y diez meses, quien fue llevado por sus padres al Servicio de Urgencias de Pediatría de un hospital de tercer nivel por un cuadro clínico de dos días de evolución que se inició con eritema en el párpado inferior del ojo derecho y fue en aumento asociado a edema progresivo y secreción purulenta ipsilateral. La madre refirió varios picos febriles cuantificados en $38{ }^{\circ} \mathrm{C}$, por lo que administró acetaminofén como antipirético, sin encontrar mejoría. Fue evaluado en Urgencias, donde se encontró, al momento del examen físico, un paciente estable, taquicárdico y afebril. Se observó edema, eritema, calor y salida de secreción purulenta en el ojo derecho, el ojo izquierdo sin alteraciones y no se evidenció compromiso de movimientos oculares; la otoscopia bilateral 
estaba dentro de los parámetros normales. Faringe sin alteraciones, no se evidenciaron adenomegalias en el cuello y el resto del examen físico estaba dentro de los parámetros normales.

El paciente fue hospitalizado con impresión diagnóstica de celulitis periorbitaria y se inició oxacilina intravenosa como manejo antibiótico empírico para esta patología en dosis de $200 \mathrm{mg} /$ $\mathrm{kg} /$ día divida en cuatro tomas.

Los análisis para clínicos solicitados mostraron hemograma con leucocitos: $13500 \mathrm{~mm}^{3}$; neutrófilos: $76 \%$; linfocitos: $22 \%$; hematocrito: $35,3 \%$; hemoglobina: $12,5 \mathrm{~g} / \mathrm{dl}$; plaquetas: $503000 \mathrm{~mm}^{3}$; neutrofilia y trombocitosis; proteína $C$ reactiva (PCR):13,4 mg/L (positiva); tomografía axial computarizada (TAC) de órbitas con aumento del volumen y engrosamiento de los tejidos blandos preseptales derechos; engrosamiento mucoso en las celdillas etmoidales anteriores ipsilaterales y en los antros maxilares, sin alteraciones del nervio óptico ni de la órbita (Figura 1).Con estos hallazgos, se continuó el manejo instaurado y se descartó compromiso de periostio y órbita.

Fue evaluado por el Servicio de Otorrinolaringología, quienes descartaron sinusitis como probable causa de celulitis periorbitaria, debido a que, en la TAC, no se observó ocupación de los senos paranasales. Debido a la evolución estacionaria del paciente, que consistió enla persistencia de cambios inflamatorios, de secreción y limitación para la apertura ocular, al tercer día de hospitalización,se tomó un cultivo de la secreción oftálmica (ya que el paciente, concomitantemente, presentó conjuntivitis purulenta), se aisló Neisseria gonorrhoeae y se escalonó el manejo antibiótico con ceftriaxona en dosis de $100 \mathrm{mg} / \mathrm{kg} /$ día intravenosa divida en dos tomas.

Dado el agente reportado, se sospechó un posible caso de abuso sexual, por lo cual se hizo una intervención multidisciplinaria entre Pediatría, Psicología, Psiquiatría y Trabajo Social, que interrogaron a los familiares y acompañantes del paciente, entre estos a la madre, quien comentó que, en una fiesta infantil, dos días antes de iniciar el cuadro clínico, al paciente se le había aplicado pintura facial en los párpados. Además, se solicitó serología para sífilis y ensayo por inmunoabsorción ligado a enzimas (enzymelinked immunosorbent assay; ELISA, por sus siglas en inglés) para virus de la inmunodeficiencia humana (VIH), las cuales fueron negativas. Luego de evaluarlas condiciones sociodemográficas del paciente, datos antiguos de la historia clínica, el estado físico y emocional del paciente, se determinó que no había sido víctima de abuso sexual. Por parte del grupo multidisciplinario, se intentó localizar a los organizadores de la fiesta infantil en primera instancia, pero esto no fue posible. Se le dieron recomendaciones a la madre del paciente para informar a su comunidad ante síntomas similares, pero no se obtuvo ninguna respuesta.

FIGURA 1. Tomografía axial computarizada de órbitas. A. corte sagital, B. corte axial. La flecha muestra un aumento del volumen y engrosamiento de los tejidos blandos preseptales en la región periorbitaria derecha. En la imagen, se observa un engrosamiento mucoso en las celdillas etmoidales anteriores (1) ipsilaterales y en los antros maxilares (2). No hay evidencia de alteraciones en la grasa retroorbitaria (3) ni en el globo ocular o en los músculos extraoculares, y el nervio óptico (4) presenta características normales. En la órbita izquierda, el aspecto es corriente.
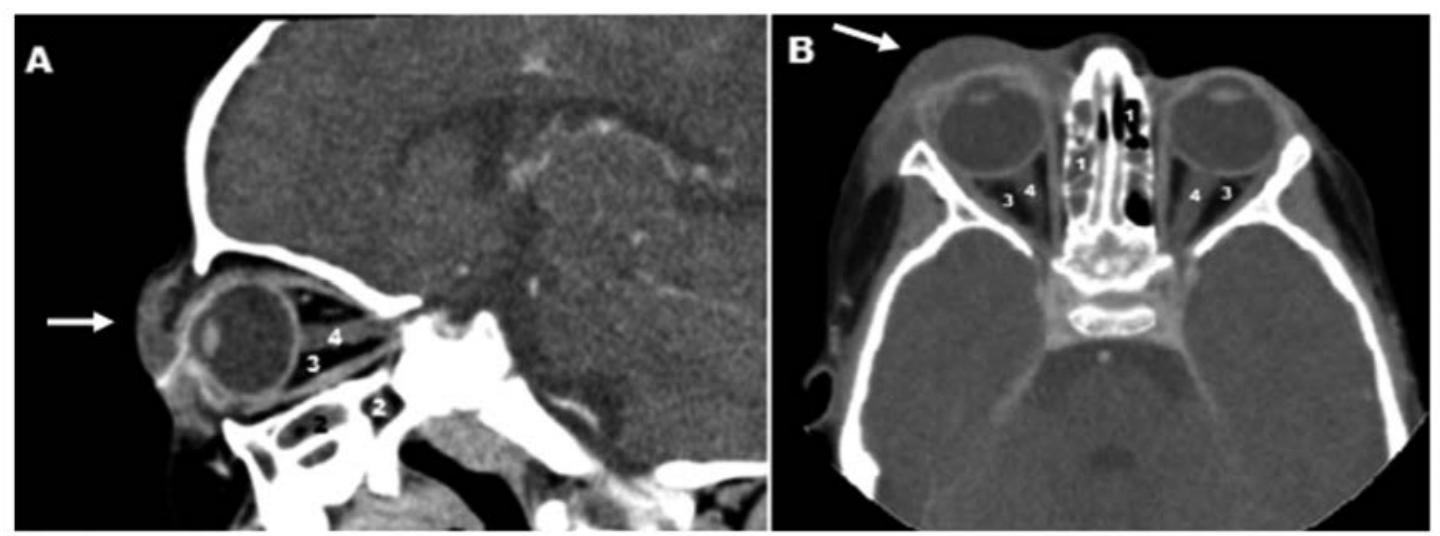
Se continuó el manejo instaurado con ceftriaxona y se obtuvo una evolución satisfactoria. Se dio el alta luego de seis días de manejo antibiótico intravenoso con indicación médica para completar 10 días de tratamiento antibiótico ambulatorio oral con ampicilina sulbactam en dosis de $50 \mathrm{mg} / \mathrm{kg} /$ día repartida en dos dosis.

\section{DISCUSIÓN}

La celulitis periorbitaria es más frecuente que la orbitaria, y ambas se presentan más en niños que en adultos. ${ }^{3}$ Entre los agentes etiológicos más usuales en esta patología, se encuentran cocos Gram-positivos, como Staphylococcus aureus, especies de Streptococcus y Peptostreptococcus. Antes de la introducción de la vacuna contra Haemophilus influenzae, este era uno de los microorganismos más frecuentes. ${ }^{4}$

Entre las vías de transmisión de la celulitis periorbitaria, se encuentran bacteremias, infecciones en focos distantes, extensión de infecciones de tejidos contiguos, como senos paranasales, inflamación dentaria, conjuntivas o lesiones en la piel. ${ }^{5} \mathrm{Al}$ realizar el examen físico, es importante que se haga una correcta inspección de los tejidos adyacentes para buscaralgún tipo de infección o traumatismo; lossíntomas respiratorios o halitosis pueden sugerir un factor de riesgo, como sinusitis. ${ }^{6}$

En la mayoría de los casos, la afección es unilateral; solo en, aproximadamente, $5 \%$ es bilateral. Se debe realizar una TAC de órbitas, ya que,entre las complicaciones, se encuentran el compromiso de la órbita, abscesos cerebrales y trombosis del seno cavernoso. ${ }^{6}$

Con lo anteriormente descrito, a nuestro paciente se le hizo el diagnóstico de celulitis periorbitaria y se inició antibiótico empírico (oxacilina), que cubría los agentes microbianos más frecuentes en esta patología. Sin embargo, por la evolución estacionaria, se decidió hacer un cultivo de la secreción ocular, que permitió la detección de Neisseria gonorrhoeae como agente causal, y se cambió el manejo a ceftriaxona.

Se han reportado casos de celulitis tanto orbitaria como periorbitaria por Neisseria gonorrhoeae en adultos. En los casos revisados, no se identificaron lesiones previas, sinusitis o cuerpo extraño en la órbita; en algunos de estos, había historia de relaciones sexuales previas sin protección. ${ }^{4,7,8} \mathrm{En}$ niños, se ha encontrado como agente causal de conjuntivitis bacteriana y esto debe hacer sospechar un posible caso de abuso sexual., ${ }^{90}$
La transmisión de este diplococo Gramnegativo se hace a través de contacto manual, directo con secreciones genitales infectadas. La bacteria se adhiere a las células epiteliales cilíndricas por medio de fimbrias, penetran la membrana basal y se multiplican. ${ }^{4}$ El manejo recomendado para este microorganismo en los casos de conjuntivitis neonatal es ceftriaxona en dosis de $25-50 \mathrm{mg} / \mathrm{kg}$ intravenosa o intramuscular. ${ }^{11}$ Se ha visto que Neisseria gonorrhoeae es una bacteria que puede sobrevivir en superficies inanimadas de 1 a 3 días y su supervivencia puede ser mayor si se encuentra a temperaturas bajas, entre $4^{\circ} \mathrm{C}$ y $6^{\circ} \mathrm{C}^{12}$

Considerando lo descrito en la literatura, se sospechó, en este paciente, abuso sexual y se intervino de manera adecuada según los reglamentos y protocolos institucionales y de acuerdo conlos lineamientos exigidos por el Gobierno nacional. Los análisis paraclínicos mostraron serología para sífilis y prueba de VIH negativas. En este caso, luego de una evaluación exhaustiva, se descartó abuso sexual.

Nuestro paciente contaba con el antecedente de la aplicación de pintura facial; es posible que fómites contaminados con el microorganismo hayan facilitado la infección. Se consideró que la infección conjuntival por un germen atípico fue la causa de la celulitis periorbitaria, ya que se descartó sinusitis por los hallazgos descritos en la TAC y no existieron lesiones en la piel adyacentes. Es muy rara la presentación de este tipo de casos, sobre todo, en población pediátrica, ya que este agente, usualmente, se asocia a conjuntivitis purulenta del neonato por su paso por el canal vaginal o a conjuntivitis bacteriana en adolescentes sexualmente activos. ${ }^{9}$

En este caso, se logró la determinación del agente causal gracias a los resultados obtenidos a partir del cultivo de secreción purulenta, pero la asociación de conjuntivitis purulenta con celulitis periorbitaria es infrecuente, ${ }^{13}$ por lo cual se recomienda que, ante un caso de características similares al presentado, se envíen muestras de la secreción al Laboratorio de Microbiología. En este grupo etario, este agente produce, con mayor frecuencia, vaginitis o vulvovaginitis, uretritis, proctitis, faringitis y artritis gonocócica. ${ }^{14}$

\section{Agradecimientos}

Agradecemos al Instituto Roosevelt por el apoyo a la investigación. 


\section{REFERENCIAS}

1. Gimeno Sánchez I, Rojo Conejo P. Celulitis preseptal y orbitaria. An Pediatr Contin 2014;12(6):284-8.

2. Rashed F, Cannon A, Heaton PA, et al. Diagnosis, management and treatment of orbital and periorbital cellulitis in children. Emerg Nurse 2016;24(1):30-5.

3. Ambati BK, Ambati J, Azar N, et al. Periorbital and orbital cellulitis before and after the advent of Haemophilus influenzae type B vaccination. Ophthalmology 2000;107(8):1450-3.

4. Raja NS, Singh NN. Bilateral orbital cellulitis due to Neisseria gonorrhoeae and Staphylococcus aureus: a previously unreported case. J Med Microbiol 2005;54(Pt 6):609-11.

5. Gómez Campdera JA, Navarro Gómez ML, García-Mon Marañes F, et al. Celulitis orbitarias y periorbitarias en la infancia. Revisión de 116 casos. An Esp Pediatr 1996;44(1):29-34.

6. Arteaga Bonilla R, Arteaga Michel R. Celulitis preseptal y orbitaria. Rev Soc Bol Ped 2003;42(3):180-3.

7. Henderson TR, Booth AP, Morrell AJ. Neisseria gonorrhoeae: a previously unreported cause of pre-septal cellulitis. Eye (Lond) 1997;11(Pt 1):130-2.
8. Yao HY, Wang CH. Preseptal cellulitis caused by Neisseria gonorrhoeae: A rare disease need to be vigilant. J Microbiol Immunol Infect2015:S1684-1182(15)00780-X. [Epub ahead of print]

9. Yetman RJ, Coody DK. Conjunctivitis: a practice guideline. J Pediatr Health Care 1997;11(5):238-41.

10. Promelle V, Bennai D, Drimbea A, et al. Pediatric orbital cellulitis without sinusitis: report of four cases.JFr Ophtalmol 2014;37(2):149-54

11. Workowski KA, Bolan GA. Sexually transmitted diseases treatment guidelines, 2015. MMWR Recomm Rep 2015;64(RR03):1-137.

12. Castañeda NarváezJL, Ordoñez Ortega J. La supervivencia de los gérmenes intrahospitalarios en superficies inanimadas. Rev Enfer Infec Pediatr 2014;27(107):394-6.

13. Sosa J, Llanes R, Rodriguez W, et al. Characterization of Neisseria gonorrhoeae strains isolated from patients with conjunctivitis. Mem Inst Oswaldo Cruz 2000;95(6):853-4.

14. Woods CR. Gonococcal infections in neonates and young children. Semin Pediatr Infect Dis 2005;16(4):258-70. 